\title{
O ensino de frações via resolução de problemas na formação de futuras professoras de pedagogia
}

\author{
The teaching of fractions via problem solving in the formation of future \\ pedagogy of teachers
}

\begin{abstract}
Resumo
Neste artigo, apresentamos uma pesquisa que teve como objetivo favorecer a compreensão do ensino de frações via resolução de problemas a futuras professoras de Pedagogia. Após uma formação realizada no início da disciplina de Metodologia de Ensino de Matemática, aplicamos uma situação e, ao final da disciplina, outra situação, a 25 licenciandas as quais deveriam apresentar explicações de como conduziriam o ensino de frações na abordagem da resolução de problemas. Para analisar essas explicações, foram elaboradas quatro categorias, caracterizadas como aspectos de referência no ensino. Os resultados mostraram que, inicialmente, 36\% apresentaram uma condução de aulas que contemplou esses quatro aspectos, sendo que, ao final, essa porcentagem aumentou para apenas $44 \%$. Além disso, ao final, $40 \%$ não propuseram o problema como ponto de partida. Concluímos que, apesar da formação proporcionada, tais aspectos foram pouco compreendidos pelas participantes, principalmente o de se propor o problema como ponto de partida.
\end{abstract}

Palavras-chave: Frações. Resolução de Problemas. Pedagogia. Formação de Professores dos Anos Iniciais.

\begin{abstract}
This article presents a research that aimed to promote understanding of the teaching of fractions via problem solving for future Pedagogy teachers. After a training held at the beginning of the Mathematics Teaching Methodology course, we applied a situation and, at the end of the discipline, another situation, which the 25 undergraduate should provide explanations of how they lead the teaching of fractions in the approach to problem solving. To analyze these explanations, four categories were prepared, characterized as reference aspects in teaching. The results showed that, initially, 36\% had classroom practices that included these four aspects, and in the end, this percentage increased to only $44 \%$. In addition to that, by the end, $40 \%$ did not propose the problem as a starting point. We conclude that, despite the training provided, these aspects were poorly understood by the participants, especially when proposing the problem as a starting point.
\end{abstract}

Keywords: Fractions. Problem Solving. Pedagogy. Teacher Education in the Initial Years.

\footnotetext{
* Doutor pela Universidade Estadual Paulista (UNESP). Professor Adjunto do Departamento de Matemática da Universidade Estadual de Maringá/UEM, Maringá, Paraná, Brasil. Endereço: Avenida Colombo, 5790, Bloco F67, Departamento de Matemática, $1^{\circ}$ andar, sala 118, Jardim Universitário, 87020-900, Maringá, Paraná, Brasil. E-mail: mcproenca@uem.br
} 


\section{Introdução}

Diversas pesquisas evidenciaram os conhecimentos profissionais de professores quando o assunto é o ensino e a aprendizagem de conteúdos de Matemática. Especificamente sobre a formação de professores e futuros professores de Pedagogia ao ensino de Matemática nos anos iniciais, encontramos pesquisas que mostraram que há uma lacuna nos conhecimentos do conteúdo de frações, bem como lacunas e mesmo a falta no conhecimento pedagógico do conteúdo no que tange à abordagem da resolução de problemas.

Na pesquisa de Campos, Magina e Nunes (2006), após analisarem as resoluções de alunos em quatro problemas de fração, 70 professores de Pedagogia foram solicitados a propor estratégias de ensino que ajudassem esses estudantes a superar as dificuldades encontradas. Os dados mostraram que as estratégias de ensino se limitaram ao uso de desenho e de material concreto, sendo verificadas, de modo geral, dificuldades dos professores no conceito de razão e de representação fracionária, bem como da conexão entre ambos.

O estudo de Marques (2013) mostrou que três professoras dos anos iniciais exerciam suas práticas de ensino de Matemática baseadas no uso do livro didático e por meio de aulas expositivas. Apesar de uma das professoras indicar a abordagem de problemas, a observação de suas aulas mostrou que, primeiro, dava tempo aos alunos para conseguirem um domínio nas quatro operações trabalhadas para, em seguida, iniciar um trabalho com problemas, envolvendo uma ou mais operações.

Esse tipo de trabalho em que problemas são apresentados após domínio de conteúdo é uma forma inadequada de abordagem da resolução de problemas, denominada de "ensinar para resolução de problemas" (SCHROEDER; LESTER, 1989, p. 34). Conforme se explicita nos Parâmetros Curriculares Nacionais de Matemática (BRASIL, 1997), o problema deve ser o ponto de partida no ensino e não as definições, regras, técnicas, levando o aluno a aprender, simplesmente, por reprodução/imitação.

Santos, Ortigão e Aguiar (2014), tendo em vista as expectativas de aprendizagem contidas nos Parâmetros Curriculares para a Educação Básica do Estado de Pernambuco, mostraram que reconhecer frações como razões, compreender relações entre metades, quartos e oitavos, e relacionar frações a pontos na reta numérica e vice-versa estiveram entre as menos indicadas pelos 112 participantes para serem ensinadas nos anos iniciais.

Do ponto de vista do conhecimento pedagógico, os autores supracitados mostraram que tais participantes se sentiam mais a vontade sobre expectativas de aprendizagem que envolviam habilidades mais simples como ler, descrever e associar, sendo que habilidades 
como resolver e elaborar problemas, compreender, relacionar e discutir receberam menos indicações pelos professores.

A pesquisa de Campos e Silva (2009) mostrou que, na questão que solicitava a fração resultante na divisão igual entre quatro crianças de três barras de chocolate, 29,41\% dos 17 pedagogos apresentaram a reposta correta. Essa mesma questão foi utilizada na pesquisa de Menegazzi (2013) para investigar conhecimentos de estudantes do quarto semestre de Pedagogia e mostrou que apenas um dos sete participantes conseguiu apresentar duas representações visuais de frações de forma corretas.

Além das lacunas no conhecimento de frações e da falta de conhecimento do trabalho baseado na resolução de problemas de professores dos anos iniciais, percebe-se que isso já vem ocorrendo na formação inicial. Costa e Poloni (2012) também investigaram estudantes do último semestre do curso de Pedagogia e mostraram que os 30 participantes, de cinco universidades particulares, indicaram os itens problemas envolvendo números fracionários e operações com números fracionários como os dois dos três itens, dentre os 11 apresentados, que menos se sentiam preparados para ensinar. De modo geral, 53,3\% desses participantes indicaram estar insatisfatoriamente preparados ou totalmente despreparados para elaborar e planejar aulas de Matemática.

Um estudo longitudinal, ao longo dos quatro anos de um curso de Pedagogia da Faculdade de Ciências e Tecnologia da UNESP - Presidente Prudente, foi realizado por Ortega e Santos (2012), evidenciando, dentro das sugestões dos nove participantes sobre metodologias de ensino, indicações que não contemplavam a abordagem da resolução de problemas. Foram propostas sugestões mais gerais de conhecimentos pedagógicos como, por exemplo, preparar aulas dinâmicas e de se utilizar uma diversidade de materiais.

Diante dos resultados das pesquisas anteriormente apresentadas, percebe-se que a formação de professores e futuros professores de Pedagogia evidencia conhecimentos ainda a serem desenvolvidos. Neste artigo, nosso foco foi a respeito dos futuros professores dos anos iniciais, tendo como objetivo favorecer-lhes a compreensão do ensino de frações via resolução de problemas no contexto da disciplina de Metodologia de Ensino de Matemática.

Outro fator que nos motivou a realizar este estudo foi, justamente, em relação às nossas investigações e experiências voltadas à temática da resolução de problemas no ensino de Matemática. As investigações envolveram alunos do Ensino Fundamental, Ensino Médio e Licenciatura em Matemática (PIROLA et al., 2006; PROENÇA; PIROLA, 2011; PROENÇA, 2013a; PROENÇA, 2013b; PROENÇA; PIROLA, 2014). 
O estudo recente mostra as nossas experiências na realização de um curso sobre resolução de problemas, ministrado a licenciandos em Matemática, os quais tiveram que elaborar sequências didáticas nessa temática e implementá-las em suas regências de aula no estágio. Pudemos verificar dificuldades na condução dessas regências como, por exemplo, propor o problema como ponto de partida no ensino, e identificar dificuldades que geraram obstáculos nessa condução que foi a falta de conhecimentos matemáticos básicos dos alunos (PROENÇA; PIROLA, 2014).

Além disso, as nossas experiências ocorreram e vêm ocorrendo no campo da formação continuada, especificamente no Programa de Desenvolvimento Educacional do Estado do Paraná (PDE-PR). Na atuação de professor orientador da área de Matemática, desde 2012, desenvolvemos produções didático-pedagógicas direcionadas à elaboração de aulas na abordagem da resolução de problemas de vários conteúdos, buscando favorecer aos professores da escola conhecimentos sobre essa abordagem de ensino. Concomitante a essa atividade, também é ministrado um curso específico sobre a resolução de problemas no ensino de Matemática.

Tais conhecimentos e experiências nos levaram (e ainda nos levam) a repensar como a resolução de problemas poderia ser trabalhada nas aulas de Matemática de forma a se ampliar a compreensão de conceitos e procedimentos matemáticos, favorecendo, assim, um ambiente propício à valorização dos conhecimentos dos alunos e ao desenvolvimento de atitudes positivas à aprendizagem.

Alguns questionamentos que se apresentam são os seguintes: como as atividades propostas no livro didático poderiam ser utilizadas de modo que pudessem ser tratadas na perspectiva da resolução de problemas? Quais critérios professores da escola utilizam para selecionar as atividades de Matemática, quando indicam trabalhar nessa perspectiva de ensino? De que forma o trabalho envolvendo o problema como ponto de partida no ensino poderia ajudar a desenvolver habilidades de pensamento como, por exemplo, o processo de generalização? Como um ensino baseado na resolução de problemas poderia ser desenvolvido em sala de aula de modo a favorecer a compreensão de Matemática dos alunos?

Desse modo, tais questionamentos evidenciam a importância de se proporcionar uma formação adequada aos futuros professores de Pedagogia para tratar da resolução de problemas nos anos iniciais do Ensino Fundamental.

\section{A formação em Pedagogia e o ensino de Matemática}


Nas Diretrizes Curriculares Nacionais para o curso de Pedagogia (BRASIL, 2006), verifica-se que o egresso deve estar apto a realizar, entre outras ações, pesquisas sobre processos de ensinar e aprender, sobre propostas curriculares, sobre a organização de práticas pedagógicas. Além disso, tais Diretrizes apontam que a estrutura dos cursos deve constituirse, por exemplo, de um núcleo de estudos básicos, articulando, entre outros conhecimentos:

\section{[...] observação, análise, planejamento, implementação e avaliação de processos educativos e de experiências educacionais, em ambientes escolares e não-escolares; estudo da Didática, de teorias e metodologias pedagógicas, de processos de organização do trabalho docente; decodificação e utilização de códigos de diferentes linguagens utilizadas por crianças, além do trabalho didático com conteúdos, pertinentes aos primeiros anos de escolarização, relativos à Língua Portuguesa, Matemática, Ciências, História e Geografia, Artes, Educação Física. (BRASIL, 2006, p. 03, grifo nosso).}

No que se refere ao ensino e à aprendizagem da Matemática, do ponto de vista dos conhecimentos sobre teorias e metodologias pedagógicas, bem como o trabalho didático com conteúdos pertinentes aos primeiros anos de escolarização, entende-se que o ensino de frações e a abordagem da resolução de problemas, temas foco deste artigo, constituem-se como parte integrante do currículo e do ensino em sala de aula.

Nos Parâmetros Curriculares Nacionais de Matemática dos $1^{\circ}$ e $2^{\circ}$ Ciclos do Ensino Fundamental (BRASIL, 1997), indica-se um trabalho com conteúdos de frações direcionado, entre outras articulações, à relação parte-todo, à leitura, à escrita e às comparações, às diferentes representações fracionárias de um mesmo número, à fração como um operador, às frações equivalentes, às representações gráficas, às operações aritméticas e à exploração em situações-problema. Nesse documento, para ensinar e aprender Matemática, a resolução de problemas é um dos caminhos propostos, sendo um dos seus princípios o seguinte:

[...] o ponto de partida da atividade matemática não é a definição, mas o problema. No processo de ensino e aprendizagem, conceitos, idéias e métodos matemáticos devem ser abordados mediante a exploração de problemas, ou seja, de situações em que os alunos precisem desenvolver algum tipo de estratégia para resolvê-las. (BRASIL, 1997, p. 32).

Diante disso, é importante que os cursos de Pedagogia abordem, justamente, uma formação ao ensino de conteúdos de Matemática por meio da resolução de problemas. No entanto, ainda se verificam cursos pouco estruturados para tal.

Um exemplo é a pesquisa de Cruz (2011), a qual, por meio da análise da forma como as disciplinas de formação específica de conteúdo estavam sendo trabalhadas na formação de futuros professores de Pedagogia de quatro instituições de ensino superior, mostrou que a formação específica em Língua Portuguesa, Matemática, História, Geografia e Ciências não estava assegurando o domínio dos conteúdos dessas áreas e, tampouco, estavam sendo 
articulados às metodologias de ensino. No caso da análise das ementas das disciplinas dos cursos, verificou-se que nas de Fundamentos e Metodologia de Matemática constavam os fundamentos ligados ao ensino e à aprendizagem, mas sem indicação de conteúdos. Os resultados evidenciaram que, por exemplo, o trabalho baseado na resolução de problemas não estava explícito nessas ementas.

O estudo referido evidencia que, por exemplo, se não for abordado o conteúdo de frações no curso de formação em Pedagogia, então será difícil favorecer uma compreensão aos futuros professores para abordá-lo, especificamente, na perspectiva da resolução de problemas. Conforme apontou Shulman (1987, p. 07), “[...] a aprendizagem do assunto da matéria não é frequentemente um fim em si mesma, mas antes um veículo empregado no serviço de outras metas". Além de metas centrais, como a de levar os alunos a compreender e resolver problemas, incluem-se as de levá-los a aprender fatos, princípios e as regras de procedimentos matemáticos.

Do ponto de vista do desenvolvimento de conhecimentos profissionais do professor, um curso de formação inicial de professores, em especial o de Pedagogia, deveria, na visão de Shulman (1986, 1987), desenvolver uma base de conhecimento ao ensino. Diante disso, esse autor apresentou uma perspectiva sobre o conhecimento do conteúdo no ensino, baseada em três categorias: (a) conhecimento do assunto da matéria; (b) conhecimento pedagógico do conteúdo; (c) e conhecimento curricular.

De acordo com Shulman (1986), o conhecimento do assunto da matéria envolve o conhecimento e entendimento da estrutura do conteúdo a ser ensinado, dos princípios de organização conceitual e dos princípios de investigação que ajudam a compreender questões relacionadas ao seu campo histórico e filosófico. O Conhecimento pedagógico do conteúdo corresponde ao ensino de um tópico de uma área específica de conteúdo por meio do uso de formas de representação de ideias, de analogias, ilustrações, exemplos, demonstrações e explanações, buscando favorecer a aprendizagem. Por fim, o conhecimento curricular envolve o conhecimento dos materiais e programas que se destinam a tópicos específicos de um conteúdo, os quais servem como ferramentas de ofício dos professores.

Na perspectiva de Mizukami (2006), os processos formativos da docência deveriam levar em consideração uma base de conhecimento que inclua o conhecimento sobre os processos de desenvolvimento e dos contextos socioculturais dos alunos, sobre a matéria que os professores ensinam e o currículo e sobre o ensino de diferentes matérias, das formas de avaliação e das condições de manejo de classe. 
Na visão de Roldão (2007), a função específica definidora do profissional professor é caracterizada pela função de ensinar:

\begin{abstract}
A função de ensinar, caracterizadora do profissional que somos, ou que quereríamos ser, na minha perspectiva, consiste, diferentemente, em fazer com que outros adquiram saber, aprendam e se apropriem de alguma coisa. E é aí que nós, professores, somos uma profissão indispensável, e talvez cada vez mais indispensável, porque não basta pôr a informação disponível para que o outro aprenda, é preciso que haja alguém que proceda à organização e estruturação de um conjunto de ações que levem o outro a aprender. Isso é, a meu ver, o que define ensinar, o que marca a diferença desta atividade, a sua especificidade e necessidade social (ROLDÃO, 2007, p. 36, grifo nosso).
\end{abstract}

Diante dessa função específica, a autora destacou a importância de se favorecer a capacidade dos professores de conhecer, pensar e agir de modo fundamentado, de avaliar a própria ação e a dos outros. Desse modo, a abordagem da resolução de problemas no ensino, conforme indicada nos Parâmetros Curriculares, citados anteriormente, é uma forma de se proceder à organização e estruturação de ações que favoreçam a aprendizagem dos alunos e deveria ser foco na formação de professores que ensinam Matemática, nesse caso, na formação dos futuros pedagogos.

Contudo, de acordo com a base de conhecimentos proposta por Shulman (1986), a abordagem da resolução de problemas corresponderia a um conhecimento pedagógico do conteúdo no ensino. Para ser desenvolvida na formação do futuro pedagogo, propusemos trabalhá-la no ensino do conteúdo de frações, entendido como o conhecimento do assunto da matéria que, na visão de Shulman $(1986,1987)$, não deve ser trabalhado de forma isolada e, sim, articulado a uma meta. Por fim, faz parte (ou deveria fazer parte) do conhecimento curricular, uma vez que se constitui como uma abordagem de ensino, componente indispensável de um currículo.

\title{
3 A resolução de problemas no ensino-aprendizagem da Matemática
}

Sobre a temática da resolução de problemas, identificam-se dois significados importantes: o significado do que seria um problema e o significado do processo de resolução de problemas. Sobre o significado do termo problema, Brito (2006) apontou que há uma concordância na literatura que evidencia um problema como uma situação que precisa ser superado um obstáculo.

De acordo com Echeverría (1998), um problema de Matemática é aquele em que há um obstáculo entre a proposição e a meta, ou seja, uma situação em que o aluno precisa tomar uma decisão sobre os procedimentos que necessita utilizar para alcançar a solução. Para essa 
autora, problemas se diferenciam dos exercícios, e destaca que estes correspondem à repetição das operações matemáticas básicas e serviriam para automatizar e consolidar uma técnica, ou seja, não há uma tomada de decisão sobre os passos de resolução.

Sobre o processo de resolução de problemas, Brito (2006) analisou a sequência de fases/etapas propostas pelos autores Mayer (1992), Krutetskii (1976), Sternberg (2000) e Polya (1978) e apontou que esse processo segue, em síntese, as seguintes fases/etapas: representação, planejamento, execução e monitoramento. Para essa autora:

\begin{abstract}
A solução de problemas refere-se a um processo que se inicia quando o sujeito se defronta com uma determinada situação e necessita buscar alternativas para atingir uma meta; nesses casos, o sujeito se encontra frente a uma situação-problema e, a partir daí, desenvolve as etapas para atingir a solução (BRITO, 2006, p. 19).
\end{abstract}

Essas fases/etapas apresentam as seguintes características:

- Representação do problema - corresponde à compreensão do problema (CHI; GLASER, 1992). Para isso, podem ser verificados o conhecimento linguístico, o semântico e o esquemático (MAYER, 1992). Tais conhecimentos envolvem, respectivamente, a conhecer a língua portuguesa, ou seja, as palavras envolvidas; a conhecer o significado das palavras como, por exemplo, de termos matemáticos e suas relações; a reconhecer, por exemplo, que um determinado problema é um problema de área, envolvendo a fórmula área = comprimento $x$ largura, o que mostra que a pessoa tem condições de guiar a atenção e discernir entre dados relevantes e irrelevantes.

- Planejamento - envolve conhecimento estratégico para realizar a busca da solução, ou seja, encontrar um caminho para resolver um problema (MAYER, 1992). Nessa fase "você organiza estrategicamente a informação, encontrando uma representação que o habilite da melhor forma para executar sua estratégia” (STERNBERG, 2000, p.308).

- Execução - corresponde ao conhecimento procedimental, o qual envolve realizar corretamente cálculos ou estratégias de cálculo (MAYER, 1992). Além disso, envolve a realização de procedimentos como a realização correta de desenhos, diagramas e outras formas de representação.

- Monitoramento - corresponde ao ato de, após obter a solução, que seja avaliada. Essa ação equivale, também, a realizar a verificação do processo de resolução do problema. Assim, isso permite reconhecer novos problemas, redefinir o problema em questão, enxergar novas estratégias e passar a ter disponíveis novos recursos ou ampliar os existentes (STERNBERG, 2000). 
É importante destacar que tais fases/etapas não devem (não deveriam) ser tomadas como uma sequência no ensino, ou seja, acreditando-se que os alunos as seguiriam de forma linear e, assim, obtendo sucesso na resolução. Entende-se que o conhecimento do professor sobre tais fases/etapas o auxilia a avaliar e analisar as dificuldades dos alunos quando se envolvem na resolução de um problema.

Sternberg (2000) já mencionava que não basta um aluno identificar um problema como tal, mas que consiga realizar uma definição e representação do problema (compreensão do problema) que o permita resolvê-lo. Nessa mesma linha de pensamento, Chi e Glaser (1992) apontaram que representações que deixam de incorporar um ou mais aspectos do problema ou que são impróprias dificultam a resolução ou mesmo a impedem de obter a resposta.

Nesse sentido, a pesquisa de Guérios e Ligeski (2013) evidencia justamente essa não linearidade, citada anteriormente, ao mostrar a ausência de compreensão textual e/ou de conhecimento matemático de 33 alunos do nono ano do Ensino Fundamental de uma escola pública na resolução de problemas, devido suas dificuldades na leitura dos enunciados e nos conhecimentos conceituais em Matemática envolvidos. Segundo as autoras, essa situação acabou por dificultar a elaboração de estratégias de resolução pelos alunos.

Diante do exposto sobre o que corresponde a problema e ao processo de resolução de problemas, a importância principal da abordagem da resolução de problemas no ensino estaria, justamente, em levar os alunos a compreenderem a Matemática. Nesse sentido, nossa preocupação no trabalho nessa abordagem de ensino é ilustrada na pesquisa recente que desenvolvemos. Nesta, evidencia-se uma análise de regências de aula de futuros professores de Matemática que leva em consideração aspectos como o de abordar o problema como ponto de partida, de discutir as estratégias dos alunos e da participação dos alunos da escola nas aulas como reflexo do trabalho realizado (PROENÇA; PIROLA, 2014).

De acordo com Schroeder e Lester (1989, p. 39), a resolução de problemas no ensino deve (deveria) ter como objetivo desenvolver a compreensão, buscando mudar a "[...] visão estreita de que matemática é apenas uma ferramenta para resolver problemas para uma visão mais ampla de que matemática é um caminho de pensar e organizar experiências".

Na visão de Schroeder e Lester (1989), compreender Matemática corresponde à ideia de relacionar. Assim, para esses autores, essa compreensão aumenta quando o aluno é capaz de estabelecer relações entre determinada ideia matemática e uma variedade de contextos, entre as ideias matemáticas expressas em um problema e entre o problema e as ideias matemáticas implícitas. 
Desse modo, em sala de aula, dever-se-ia abordar os conteúdos tendo um problema como ponto de partida (BRASIL, 1997). Assim, o professor poderia explorar as atitudes e conhecimentos que os alunos trazem no momento em que tentam resolver problemas de Matemática, identificando, entre outros aspectos, suas dificuldades, seus avanços e seus conceitos errôneos.

Para Schroeder e Lester (1989), o problema como ponto de partida corresponde a uma abordagem no ensino que denominaram de ensinar via resolução de problemas. Esses autores apresentaram três abordagens, a saber:

- Ensinar sobre resolução de problemas: o ensino era baseado no modelo de Polya sobre o processo de resolução de problemas. Aos alunos, eram explicitamente ensinadas as quatro fases do modelo desse autor de modo que eles deveriam ter ciência delas quando resolviam problemas. Um aspecto limitante nessa abordagem seria o de pensar que tal modelo seria um tópico de Matemática que deveria ser trabalhado de forma isolada do conteúdo e das relações matemáticas. Esse tipo de ensino evidencia a forma linear de se abordar fases/etapas de resolução que criticamos anteriormente.

- Ensinar para resolução de problemas: corresponde a um ensino que se direciona, primeiro, a levar os alunos a aprenderem conteúdos de matemática para, somente depois, aplicarem em problemas e exercícios. Trata-se de um limite maior no ensino, uma vez que a "resolução de problemas é vista como uma atividade em que os alunos somente se engajam depois da introdução de um novo conceito ou para seguir uma habilidade de cálculo ou um algoritmo" (SCHROEDER; LESTER, 1989, p. 34, grifo dos autores).

- Ensinar via resolução de problemas: corresponde a um ensino que preza pela utilização de problemas como primeiro passo para aprender Matemática. De acordo com Schroeder e Lester (1989), nesse ensino, pode-se ajudar os alunos a compreender os conceitos, processos e técnicas matemáticos. Nesse sentido:

O ensino de um tópico matemático começa com uma situação-problema que expressa aspectos-chave desse tópico e técnicas matemáticas são desenvolvidas como respostas razoáveis para problemas razoáveis. Um objetivo de se aprender matemática é o de poder transformar certos problemas não rotineiros em problemas rotineiros. A aprendizagem da matemática, desse modo, pode ser vista como um movimento do concreto (um problema do mundo real que serve como exemplo do conceito ou da técnica matemática) para o abstrato (uma representação simbólica de uma classe de problemas e técnicas para operar com esses símbolos). (SCHROEDER; LESTER, 1989, p. 33, grifo nosso). 
A passagem do concreto para o abstrato pode ser entendida como a articulação entre os conhecimentos prévios dos alunos sobre a Matemática aprendida e o novo conhecimento, a simbologia e/ou estrutura da Matemática que se quer ensinar. Desse modo, Carlini (2004) destacou que nessa abordagem a resolução de problemas permite que se alcancem objetivos de natureza conceitual, procedimental e atitudinal.

[...] proporciona condições para realizar objetivos conceituais (organização, relação e registro de informações diante de um problema concreto), procedimentais (busca de novas informações, formulação e testagem de hipóteses, elaboração de um plano de ação) e atitudinais (responsabilidade, cooperação, autoconfiança) (CARLINI, 2004, p. 75).

Do ponto de vista do desenvolvimento cognitivo, é importante levar os alunos a desenvolver o pensamento matemático. Esse pensamento envolveria a compreensão de processos dedutivos e indutivos, teste de hipóteses, formas de representações, relações estruturais, avaliações e monitoramento das próprias ações entre outras (CHARLES, 1985; SCHOENFELD, 1990).

A pesquisa de Fi e Degner (2012), ao buscar favorecer a compreensão sobre o ensino que adota o problema como ponto de partida, mostrou que os professores, ao se envolverem na busca de uma formalização matemática para resolver um problema permeado pelo uso de um tabuleiro de xadrez, puderam perceber a condução a ser desenvolvida em sala de aula. De modo geral, essa condução envolveria dar tempo aos alunos para propor e apresentar suas estratégias, de evidenciar os conceitos matemáticos que dominam e de se avaliar o entendimento do processo seguido. Nesse sentido, esses autores mostraram a importância dessa compreensão facultada aos professores para que, em sala de aula, possibilitem aos seus alunos se envolverem, de forma progressiva, com uma trajetória de formalizações matemáticas, permitindo, entre outros processos de pensamento, a abstração.

Diante do que foi apresentado até o momento, entende-se que a importância de um ensino baseado na resolução de problemas está em se propiciar a compreensão de Matemática dos alunos. Assim, tendo em vista o aspecto do problema, do processo de resolução de problemas e de um trabalho em sala de aula em que se adota a introdução de um tópico/assunto/conteúdo matemático por meio de um problema, seria importante, no ensino, realizar as seguintes ações:

- Propor problemas em que se admitam vários caminhos de resolução, bem como que existam várias soluções possíveis (POZO; ANGÓN, 1998).

- Evitar a ideia de se ensinar algoritmos específicos, valorizando nos alunos o “[...] conhecimento e entendimento adquiridos previamente para satisfazer as demandas de 
uma situação não familiar. $\mathrm{O}$ estudante deve sintetizar o que ele ou ela aprendeu e aplicar em novas e diferentes situações" (KRULIK; RUDNICK, 1982, p.42). De acordo com Fi e Degner (2012), os alunos precisam ter a oportunidade de utilizarem os conhecimentos e habilidades que possuem.

- Permitir que os alunos tenham tempo suficiente para explorar o problema, além de resumir os resultados que eles obtiveram, apresentando suas ideias, direcionando-os a conclusões apropriadas e reais (BURNS, 1982). Fi e Degner (2012) também concordam com a atitude de se dar tempo aos alunos para que explorem o problema. Estes autores indicaram a possibilidade de os alunos trabalharem em duplas ou em grupos antes de socializarem com toda a turma suas ideias, métodos, planos e resultados.

- Discutir possibilidades de estratégias de resolução com os alunos e requerer que eles verifiquem o problema e a resposta e que identifiquem as estratégias utilizadas (CHARLES, 1985, 1990). Essa identificação poderia permitir ao professor direcionálas a uma formalização progressiva das estratégias concretas dos alunos a estratégias abstratas, relacionadas ao conceito foco do ensino (FI; DEGNER, 2012).

Assim, o trabalho baseado na abordagem da resolução de problemas implicaria em ações baseadas em aspectos que contemplem a introdução de um problema, momento em que o professor precisa conduzir a aula de modo que os alunos articulem seus conhecimentos prévios ao problema, que discutam suas estratégias e que leve os alunos a relacionarem o que fizeram ao novo conteúdo/conceito a ser ensinado e aprendido.

\section{Metodologia}

A abordagem metodológica adotada segue os pressupostos oriundos da pesquisa qualitativa. A natureza desse tipo de investigação implica em considerar, como fonte direta de dados, o ambiente natural onde ocorrem as ações das pessoas; implica, igualmente, em uma análise descritiva por meio de palavras ou imagens, buscando abordar o mundo de forma minuciosa; implica, ademais, no interesse pelo processo de como ocorrem as ações das pessoas; implica, finalmente, em uma tendência de análise dos dados de forma indutiva (BOGDAN; BIKLEN, 1994).

O contexto da pesquisa se deu durante as aulas da disciplina de Metodologia de Ensino de Matemática $-1^{a}$ a $4^{a}$ séries do Ensino Fundamental II do curso de Pedagogia de uma 
universidade pública do Estado do Paraná, nosso ambiente natural em que ocorreram as ações dos envolvidos. Tal disciplina foi ministrada pelo autor desta pesquisa a uma turma de 28 graduandas do terceiro ano do curso, período noturno, no primeiro semestre de 2014.

O foco da presente pesquisa foi sobre o conteúdo de frações e seu ensino por meio da resolução de problemas. Tal conteúdo consta do programa da referida disciplina como o primeiro a ser estudado, a saber: números racionais na forma fracionária. Apenas no último subitem desse conteúdo é proposto um trabalho, envolvendo situações-problema e indicado para o conceito de fração e as operações com frações.

Desse modo, elaboramos e desenvolvemos aulas na abordagem da resolução de problemas, de modo que sua condução perpassasse os vários assuntos do conteúdo de frações. A exploração e discussão dos tópicos sobre o conceito de fração e sua aquisição, equivalência de frações e as quatro operações fundamentais da aritmética foram introduzidos via uma situação-problema. O objetivo foi o de favorecer às licenciandas em Pedagogia uma compreensão do trabalho baseado nessa abordagem de ensino, bem como ações a serem desenvolvidas.

Os problemas apresentados visavam que o assunto pudesse ser introduzido sem o uso direto da resolução matemática envolvida, ou seja, do algoritmo ou simbologia específicos. Assim, para cada um dos tópicos acima, buscamos, primeiro, oportunidades de resolução, respectivamente: sem o uso direto do número fracionário; sem o uso direto do m.d.c.; sem a apresentação direta dos algoritmos das operações aritméticas, evitando-se o cálculo direto do m.m.c. na adição e subtração e as resoluções específicas da multiplicação e divisão. Por exemplo, no caso do algoritmo da adição, entende-se que o aluno da escola não sabe utilizá-lo de forma direta à soma de duas frações. Assim, nosso foco, nas aulas, foi o de articular possíveis estratégias de resolução aos tópicos abordados.

Nas aulas, primeiramente, realizamos uma discussão sobre aprendizagem significativa, o que levou em consideração a importância de valorizar os conhecimentos prévios dos alunos. Essa situação foi importante porque o trabalho na abordagem da resolução de problemas envolve avaliar o aspecto das estratégias que os alunos poderiam apresentar em sala de aula.

A discussão sobre o significado de problema e do processo de resolução de problemas foi realizada após a abordagem do primeiro problema que introduziu o conceito de frações. Nesse sentido, realizamos uma identificação das etapas de resolução de problemas (compreensão, planejamento, execução, monitoramento) ao longo do desenvolvimento dos vários problemas que foram explorados. 
A cada problema apresentado, as licenciandas em Pedagogia o resolviam (em dupla ou trio) e vinham até à lousa mostrar a estratégia de resolução utilizada. Foi solicitado que apresentassem estratégias que correspondessem ao que os alunos poderiam realizar como, por exemplo, a representação via desenhos (retângulos, círculos, diagramas etc.). Quando não conseguiam propor um caminho que não fosse a forma matemática a ser abordada, eram apresentadas pelo pesquisador duas resoluções (aluno A e aluno B), de modo que uma era correta e a outra tinha algum erro em uma das etapas de resolução de problemas.

Essa condução das aulas teve como objetivo o de explorar e evidenciar o processo de resolução de um problema e o de salientar a valorização do que os alunos já sabem de matemática para utilizar nas suas estratégias. Buscamos evidenciar, sobretudo, a possibilidade de articulação entre os conhecimentos dos alunos e o novo conteúdo a ser aprendido, o que permitiu discutir, com as futuras pedagogas, a pouca contribuição de um ensino que visa à abordagem de cálculos e algoritmos matemáticos como ponto de partida.

Um exemplo dessa articulação correspondeu à adição de $\frac{3}{4} \operatorname{com} \frac{7}{10}$ que foi solicitada em um problema contextualizado sobre o percurso percorrido por dois amigos e que, primeiro, foi explorada por meio da representação de cada uma dessas frações em formato de retângulo pelas licenciandas. Após compreensão de que cada retângulo deveria ter mesma medida, pois se tratava do mesmo todo, as participantes foram conduzidas a realizar uma nova divisão desses desenhos em partes iguais, de modo que obtivessem a mesma quantidade em cada desenho e que, assim, essa nova divisão gerasse a fração equivalente de cada uma dessas duas frações. Com isso, foi possível identificar que a nova divisão em 20 partes iguais gerou, respectivamente, as frações $\frac{15}{20} \mathrm{e} \frac{14}{20}$, permitindo apresentar o algoritmo da adição por meio da articulação ao cálculo do m.m.c. na soma de frações.

Assim, nesse problema, entendemos que os conhecimentos, entre outros, sobre a fração e suas possíveis representações via desenho, e sobre fração equivalente e cálculo do m.m.c. corresponderam (e correspondem) a conhecimentos prévios. São conhecimentos que devem (deveriam) ser trazidos e retomados para a compreensão do algoritmo da adição (e nos demais) via um trabalho na abordagem da resolução de problemas.

Contudo, favorecemos uma formação que envolveu as participantes justamente na maneira que elas poderiam conduzir um ensino de frações via resolução de problemas, tendo em vista possíveis ações. Assim, ao se envolverem com a necessidade de apresentar estratégias de resolução a problemas colocados como ponto de partida no ensino dos conteúdos, de terem tido tempo para tal, de terem sido solicitadas a virem até à lousa mostrar 
suas estratégias, analisando e discutindo o processo de resolução, de terem, assim, analisado e discutido as articulações entre as estratégias e os conteúdos envolvidos, tiveram a oportunidade de compreender que se tratavam de ações a serem desenvolvidas no ensino.

No decorrer do nosso contexto de pesquisa, logo no segundo dia de aula após essa exploração e discussão da temática envolvida, foi aplicada uma avaliação com o objetivo de verificar e analisar as explicações e as dificuldades das licenciandas na condução do ensino de frações na perspectiva da resolução de problemas. Tal avaliação foi composta de três situações: a primeira situação envolvia um problema de fração equivalente a ser resolvido; a segunda, um episódio cotidiano em que a soma de frações foi feita de forma incorreta; e a terceira, uma descrição de uma condução por um professor do ensino do conceito de fração e de fração equivalente de forma expositiva. Em cada uma, foram solicitadas explicações das licenciandas de como as abordariam tendo em vista a condução por meio da resolução de problemas. A data de aplicação dessa avaliação não foi anunciada às participantes, sendo que, nesse dia, três delas não compareceram e, assim, apresentamos os resultados de 25 licenciandas da turma de Pedagogia investigada.

Como cada uma das três situações poderia evidenciar os conhecimentos constituídos pelas participantes, escolhemos a primeira situação, porque também permitia analisar suas dificuldades na resolução. Tal situação correspondeu ao exemplo de item, apresentado no documento Plano de Desenvolvimento da Educação - PDE/Prova Brasil (BRASIL, 2011), que ilustra a avaliação do percentual de respostas dos alunos do nono ano do Ensino Fundamental para identificar frações equivalentes (Descritor 23). Em tal exemplo, elaboramos uma pergunta e não apresentamos as quatro alternativas originalmente propostas, a saber: Quatro amigos, João, Pedro, Ana e Maria saíram juntos para fazer um passeio por um mesmo caminho. Até agora, João andou $\frac{6}{8}$ do caminho; Pedro, $\frac{9}{12} ;$ Ana, $\frac{3}{8}$ e Maria, $\frac{4}{6}$. Quem são os amigos que se encontram no mesmo ponto do caminho?

Desse modo, tiveram que: a) resolvê-la; $b$ ) explicar como essa atividade poderia ser desenvolvida em sala de aula para favorecer a compreensão do conceito de fração equivalente do ponto de vista da resolução de problemas.

Em aula posterior, a resolução dessa situação, que, neste artigo, passamos a denominar de situação inicial, foi trazida para discussão com a turma. Além disso, foi entregue a cada participante um questionário que lhes permitia assinalar suas dificuldades. Assim, marcaram itens referentes aos erros cometidos nas etapas de resolução de problemas como, por exemplo, se identificaram equívocos no planejamento (estratégia utilizada). Nas explicações, marcaram 
ações que faltaram na condução das aulas: se propuseram o problema como ponto de partida; se levaram em consideração que deveriam permitir que os alunos apontassem suas estratégias de resolução; se discutiram as estratégias dos alunos; se buscaram articular essas estratégias ao assunto.

Ao mesmo tempo em que discutimos o que tinham feito, e o que tínhamos estudado na disciplina sobre a abordagem do conteúdo de frações na abordagem da resolução de problemas, marcavam as dificuldades no questionário. Foi um momento de reflexão das licenciandas, de suas respostas, e da maneira que poderiam conduzir as aulas na abordagem da resolução de problemas.

Em seguida, foi dada continuidade à disciplina de Metodologia de Ensino de Matemática, tendo em vista os outros conteúdos a serem trabalhados. Assim, ao final da mesma, aplicamos uma avaliação escrita obrigatória que era exigida como um dos critérios de aprovação/reprovação. Uma das questões dessa avaliação contemplava uma situação que propusemos com o objetivo de verificar e analisar como as futuras professoras de Pedagogia conduziriam o ensino de frações na abordagem da resolução de problemas, tendo em vista a formação oferecida.

Tal atividade, denominada, neste estudo, de situação final, correspondeu à seguinte: No ensino de frações, alguns conteúdos que deveriam ser trabalhados em sala de aula são os seguintes: a) O conceito de fração e sua aquisição; b) Equivalência de frações; c) As quatro operações fundamentais (adição, subtração, multiplicação e divisão). No entanto, verifica-se que esses conteúdos são abordados em sala de aula de modo que o ponto de partida acaba sendo o ensino direto dos cálculos e algoritmos.

Desse modo, foi solicitado que respondessem: escolha um desses conteúdos acima e explique como você conduziria seu ensino em sala de aula, adotando a abordagem da resolução de problemas.

Os dados foram analisados com base em palavras e figuras, buscando-se uma descrição desses resultados (BOGDAN; BIKLEN, 1994), e com base nas porcentagens da quantidade de respostas verificadas. Assim, primeiramente, apresentamos dados sobre as estratégias utilizadas pelas licenciandas na resolução do problema da situação inicial e a nota média obtida.

A análise das explicações dadas pelas futuras pedagogas nas situações inicial e final sobre como conduziriam o ensino do conteúdo de frações na abordagem da resolução de problemas foi delimitada por meio de categorias. Desse modo, com base em nosso quadro 
teórico, elaboramos quatro categorias que caracterizamos como aspectos de referência para compor ações no ensino na abordagem da resolução de problemas, a saber:

a) Problema como ponto de partida: referente à indicação do problema como ponto de partida para introduzir o tópico/assunto de fração;

b) Permitir aos alunos expor suas estratégias: referente a possibilitar aos alunos a resolverem, sozinhos, o problema, expondo, assim, suas estratégias de resolução. Desse modo, o objetivo é o de evitar a apresentação direta de algoritmos específicos;

c) Discutir as estratégias dos alunos: corresponde a proporcionar uma discussão das estratégias/caminhos de resolução dos alunos, o que, de modo geral, leva em consideração avaliar como desenvolveram as etapas do processo de resolução;

d) Articular as estratégias dos alunos ao conteúdo: implica no uso das estratégias dos alunos como base para articular ao novo conteúdo (a um dos assuntos de fração), favorecendo, assim, sua compreensão.

Contudo, tendo em vista a análise das ações dessas futuras pedagogas nesse processo, buscamos apresentar dados que evidenciassem o modo como conduziriam aulas sobre o conteúdo de frações na abordagem da resolução de problemas.

\section{Análise das explicações das futuras pedagogas}

$\mathrm{Na}$ situação inicial, cuja resolução foi solicitada às participantes, verificou-se que obtiveram a nota média de 5,2 (escala de zero a dez pontos), considerando-se apenas notas zero ou dez porque a resolução estava totalmente correta ou não nos permitiu atribuir nota diferente de zero. Do total ( $\mathrm{n}=25), 64 \%$ tentaram resolver via desenhos (retângulos), 24\% tentaram resolver via cálculo do m.m.c., $4 \%$ via cálculo do m.d.c. e $8 \%$ deixaram em branco.

De modo específico, verificamos que, em termos de acertos, $28 \%$ conseguiram resolver via desenhos e $24 \%$, via uso do m.m.c., totalizando $52 \%$ das participantes que conseguiram resolver corretamente o problema. Em termos de erros, verificamos que a única participante (4\%) que optou pelo cálculo do máximo divisor comum (m.d.c.) utilizou os denominadores das frações, ao invés da forma correta que seria encontrar o máximo divisor comum entre numerador e denominador de uma mesma fração. Também identificamos que $36 \%$ cometeram equívocos ao representar os desenhos, sendo que cada uma das frações não foi representada por meio de um mesmo todo (caminho). A Figura 1, abaixo, exemplifica esse erro. 
Destaca-se que o fato de as participantes terem utilizado o cálculo do m.m.c., ao invés do cálculo do m.d.c., pode ser decorrente da facilidade que visualizaram para obter a resposta (ECHEVERRÍA, 1998), uma vez que, como estratégia de resolução, bastava verificar as frações que resultavam iguais, evidenciando, assim, as frações contidas no problema que eram equivalentes.

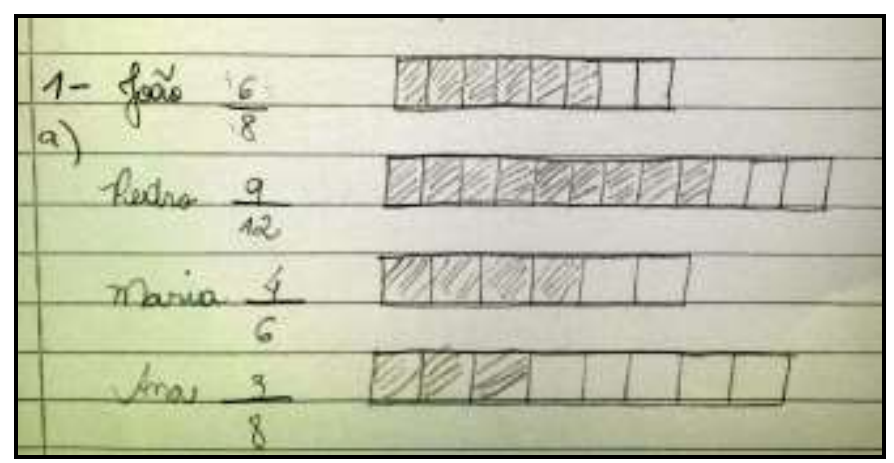

Figura 1 - Erro cometido na resolução da situação inicial

Do ponto de vista do processo de resolução de problemas, pode-se inferir que os erros via desenho corresponderam a dificuldades na etapa de representação do problema, ou seja, na compreensão do problema, o que evidenciou dificuldades no conhecimento semântico do conceito do todo. Este tipo de dificuldade foi verificado na pesquisa de Magina e Campos (2008), as quais mostraram que professoras de Pedagogia têm pouco claros os diferentes significados que as frações assumem, o que acaba levando-as a realizar estratégias limitadas de ensino.

A segunda questão da situação inicial solicitava a explicação das licenciandas de como desenvolveriam suas aulas sobre o assunto de equivalência de frações na abordagem da resolução de problemas. A Tabela 1, abaixo, mostra os resultados em termos das categorias que elencamos e que corresponderam aos aspectos analisados no ensino de frações.

Tabela 1 - Aspectos do trabalho na abordagem da resolução de problemas no ensino

\begin{tabular}{lcccc}
\hline \multirow{2}{*}{ Aspectos de referência no ensino } & \multicolumn{3}{c}{ Quantidade em \% (n = 25) } \\
\cline { 2 - 5 } & Propôs & Não propôs & Branco & Total \\
\hline Problema como ponto de partida & 76 & - & 24 & 100 \\
Permitir aos alunos expor suas estratégias & 40 & 36 & 24 & 100 \\
Discutir as estratégias dos alunos & 44 & 32 & 24 & 100 \\
Articular as estratégias dos alunos ao conteúdo & 44 & 32 & 24 & 100 \\
\hline
\end{tabular}

Conforme se observa, $76 \%$ indicaram a introdução do assunto de equivalência de frações via um problema. Verifica-se que $24 \%$ deixaram em branco suas respostas, ou seja, não apresentaram explicações sobre o ensino de frações na abordagem da resolução de problemas. 
Além disso, a Tabela 1, acima, mostra que o total de $36 \%$ não propôs o aspecto sobre permitir aos alunos de expor suas estratégias e, para os dois últimos aspectos, verificamos que essa mesma atitude se deu para o total de $32 \%$ das licenciandas. Nesse caso, identificamos, nas explicações das graduandas, a falta de menção da participação dos alunos, sendo mais evidentes apenas as ações da professora. A Figura 2, abaixo, ilustra esse dado.

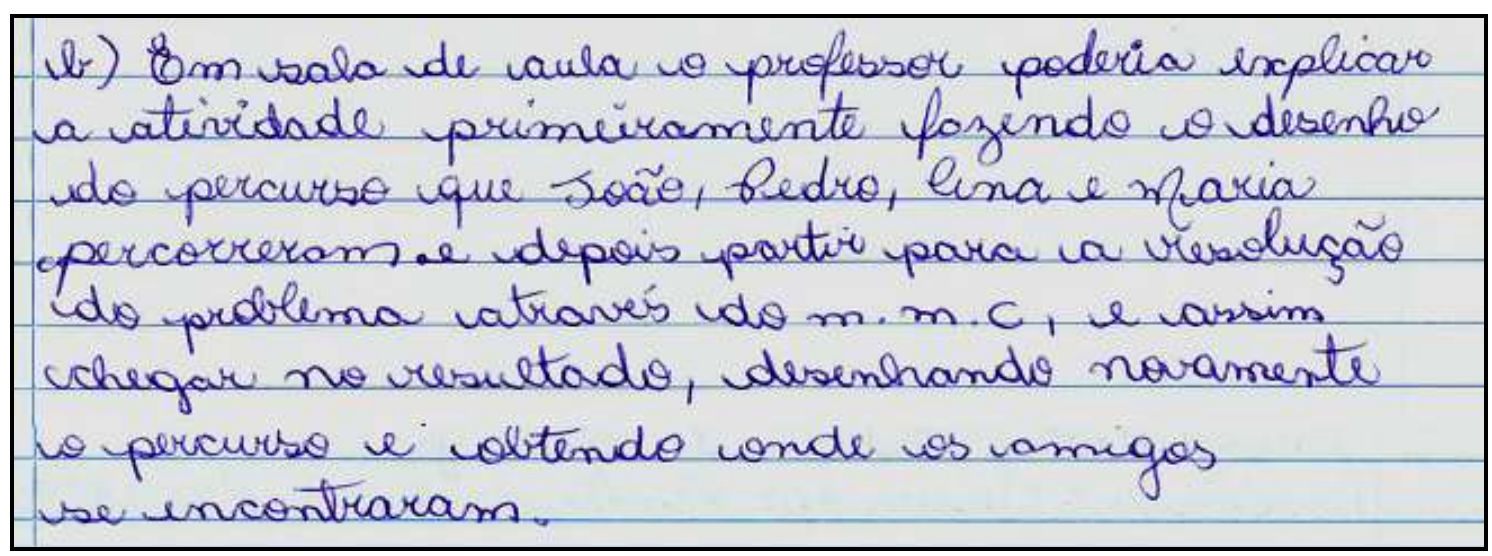

Figura 2 - Explicação que evidenciou somente a atuação da professora

Esse tipo de condução da aula no ensino em que somente o professor participa pode ser entendido como direcionado ao ensinar para resolução de problemas. Nesse caso, verifica-se a pouca valorização dos conhecimentos prévios do aluno, sendo o seu papel apenas o de aplicar o que lhe foi ensinado em novas atividades.

De modo geral, identificamos que apenas $36 \%$ das licenciandas contemplaram em suas explicações os quatro aspectos tomados como referência de nossa análise, evidenciando ações no ensino de equivalência de frações na abordagem da resolução de problemas. A Figura 3, abaixo, ilustra um exemplo desse tipo de explicação. 


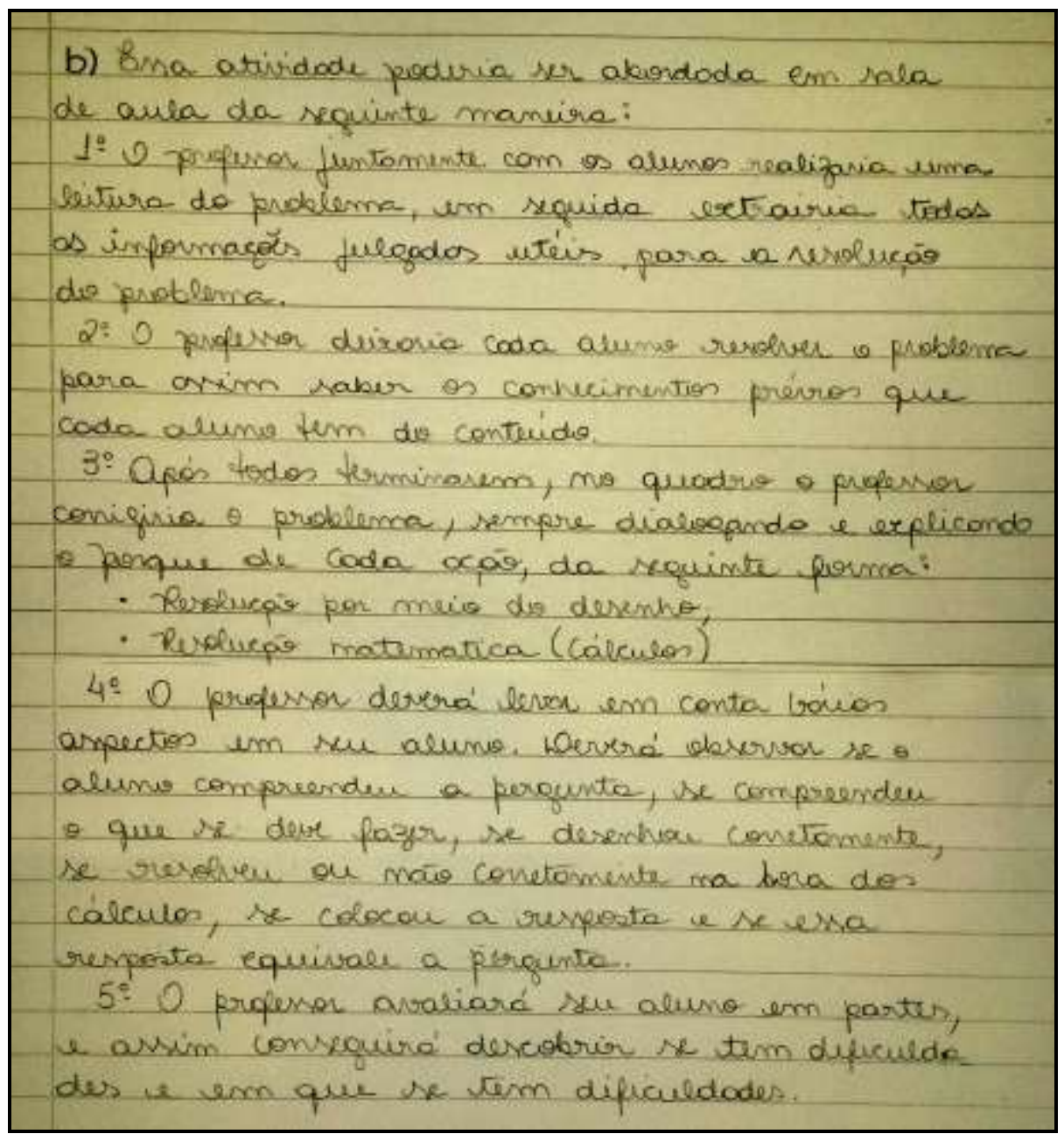

Figura 3 - Explicação que contemplou os quatro aspectos de referência no ensino

$\mathrm{Na}$ finalização das aulas da disciplina ministrada de Metodologia de Ensino de Matemática, aplicamos uma avaliação escrita obrigatória, sendo que uma de suas questões correspondeu a uma situação final que foi proposta para analisar as explicações das graduandas sobre como conduzir o ensino do conteúdo de frações na abordagem da resolução de problemas. Para descrever suas explicações, tiveram a oportunidade de escolher um assunto. Verificamos que, do total de participantes da pesquisa, 56\% escolheram o conceito de fração, $24 \%$ escolheram a equivalência de frações e $20 \%$ escolheram a operação de adição.

A Tabela 2, abaixo, mostra os resultados sobre as explicações analisadas e que foram delimitadas em termos dos aspectos que tomamos como referência no ensino baseado na abordagem da resolução de problemas sobre o conteúdo de frações.

Tabela 2 - Aspectos do trabalho na abordagem da resolução de problemas no ensino

\begin{tabular}{lcccc}
\hline \multirow{2}{*}{ Aspectos de referência no ensino } & \multicolumn{3}{c}{ Quantidade em \% (n = 25) } \\
\cline { 2 - 4 } & Propôs & Não & Branco & Total \\
\hline Problema como ponto de partida & 60 & 40 & - & 100 \\
Permitir aos alunos expor suas estratégias & 48 & 52 & - & 100 \\
Discutir as estratégias dos alunos & 48 & 52 & - & 100
\end{tabular}


Apesar de o foco das aulas terem sido na abordagem do ensinar via resolução de problemas, observamos que $40 \%$ das licenciandas não propuseram o problema como ponto de partida na introdução do assunto de fração escolhido. Dessa porcentagem, identificamos que, para iniciar a condução das aulas, 50\% apresentaram o uso de dobraduras ou desenhos, $40 \%$ definiram/conceituaram e $10 \%$ propuseram o uso do material Cuisenaire. A Figura 4, abaixo, ilustra essa situação analisada.

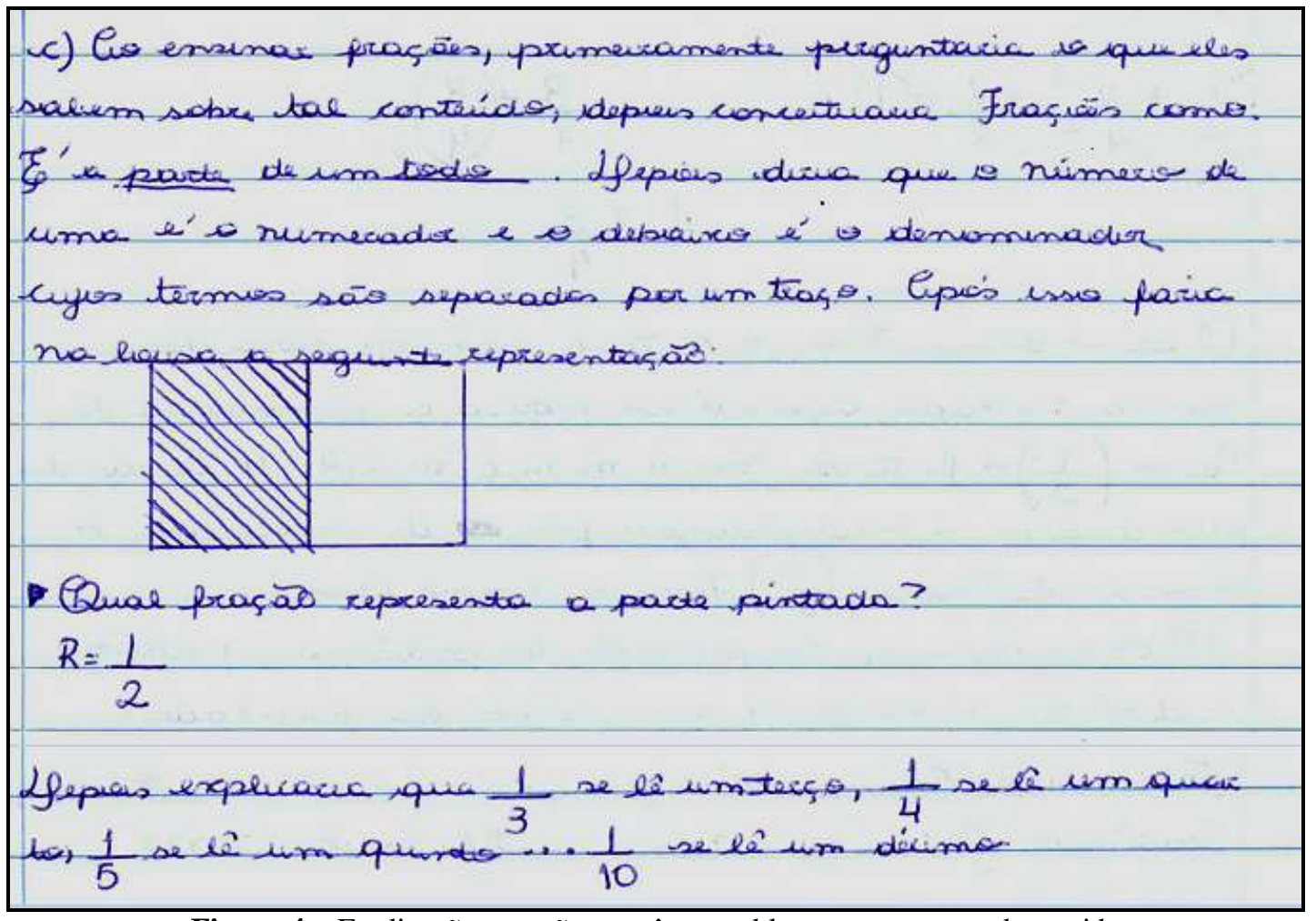

Figura 4 - Explicação que não propôs o problema como ponto de partida

Sobre o ensino de frações na escola, verificamos que se tem valorizado essas formas de condução apontadas acima. A pesquisa de Magina e Campos (2008) mostrou que professoras de Pedagogia abordavam o trabalho em sala de aula sobre o conceito de frações, limitado ao uso de desenhos e de materiais concretos.

A Figura 4, acima, também exemplifica as dificuldades das futuras professoras nos outros três aspectos de referência no ensino. De acordo com a Tabela 2, acima, na coluna não propôs, essas porcentagens $(52 \%, 52 \%$ e $44 \%)$ indicaram, de modo geral, explicações baseadas em uma condução que valorizava os conteúdos. Assim, pode-se inferir que isso se configurou como o ensinar para resolução de problemas.

De modo geral, identificamos que $44 \%$ das graduandas contemplaram em suas explicações os quatro aspectos de referência na abordagem da resolução de problemas no 
ensino do assunto de fração escolhido. Dessa porcentagem, 18,18\% indicaram o conceito de fração, 54,55\%, equivalência de frações, e 27,27\%, a adição. A Figura 5, abaixo, ilustra esse resultado.

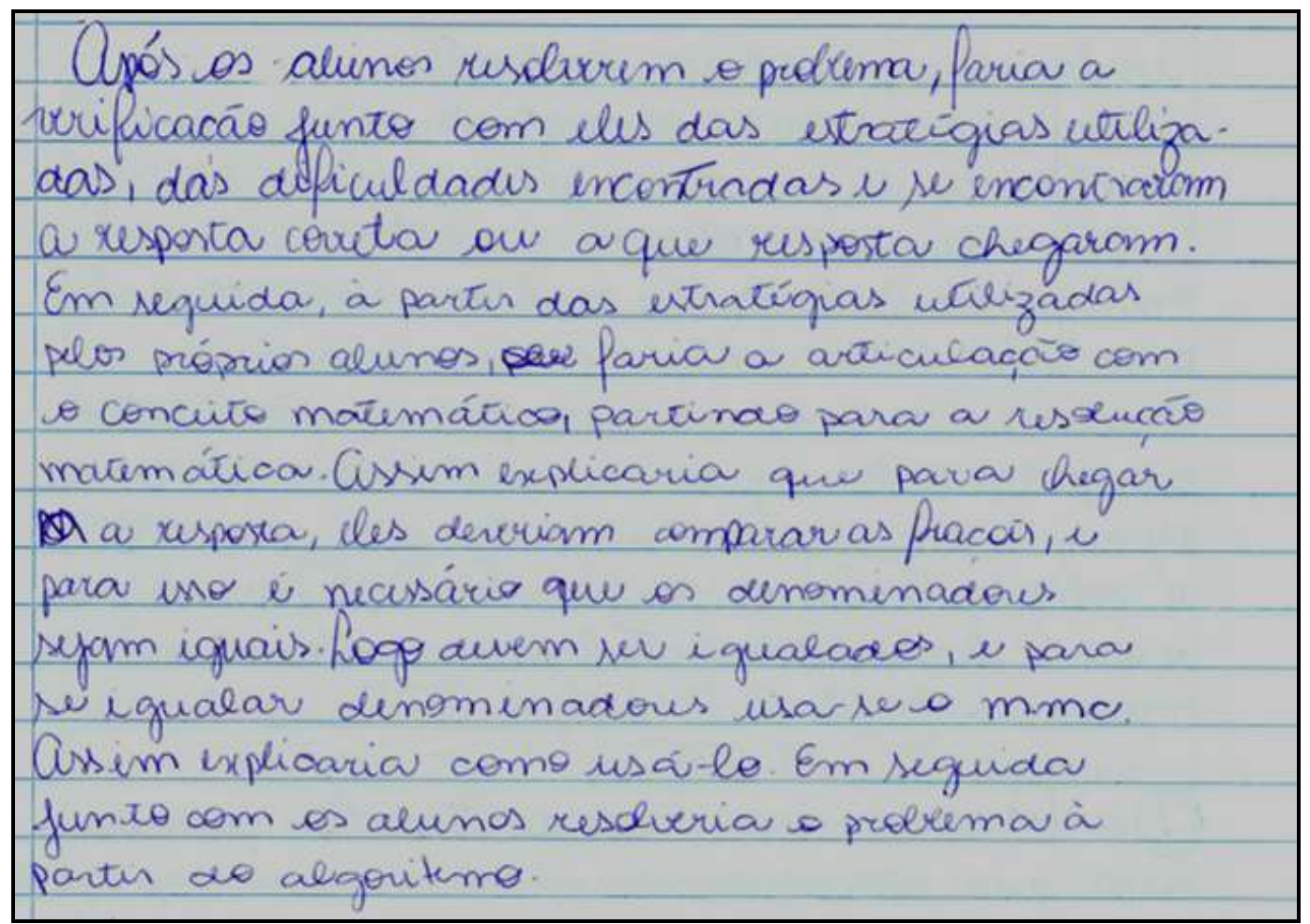

Figura 5 - Explicação que contemplou os quatro aspectos de referência no ensino

Desse modo, esses resultados evidenciaram que $44 \%$ das futuras professoras propuseram uma condução do ensino de frações baseada na abordagem da resolução de problemas, contemplando os quatro aspectos considerados.

\section{Conclusão}

A partir de um trabalho desenvolvido no contexto da disciplina de Metodologia de Ensino de Matemática, buscamos favorecer a compreensão de futuras professoras de Pedagogia sobre o ensino de frações via resolução de problemas. Para tal, verificamos as dificuldades na resolução da situação inicial, além de analisar as explicações de como conduziriam esse ensino na abordagem trabalhada após a formação oferecida e ao final da disciplina ministrada.

Verificamos dificuldades na resolução do problema apresentado na situação inicial em termos do conceito do todo (inteiro) que corresponde ao conteúdo de frações. Identificamos que $36 \%$ das licenciandas não representaram cada uma das frações envolvidas em termos do mesmo todo, ou seja, o caminho a ser percorrido que deveria ser a referência. 
Durante as aulas que foram ministradas na disciplina, o fato de se considerar o mesmo todo na resolução dos problemas propostos foi abordado. Além disso, as representações via desenho sobre esse fato e o conceito de fração foram discutidos e explorados nessas aulas. Assim, na análise da resolução desse problema que envolveu o assunto de equivalência de frações, verificamos que os conhecimentos prévios necessários sobre o reconhecimento do todo como um conhecimento do assunto da matéria ainda não estavam devidamente constituídos pelas participantes. Entendemos que isso gerou a má compreensão do problema e, assim, a realização equivocada do processo de resolução.

$\mathrm{Na}$ análise das situações inicial e final, especificamente a respeito do aspecto de referência no ensino de se propor o problema como ponto de partida, identificamos, respectivamente, as porcentagens de $76 \%$ e $60 \%$. O decréscimo nessa porcentagem indica dificuldades das licenciandas para propor esse aspecto e que deveria ter sido compreendido, pois se trata do ponto principal do ensinar via resolução de problemas.

Assim, ao final, 40\% das graduandas não mencionaram em suas explicações conduzir um ensino adotando o problema como ponto de partida. Relataram, de modo, geral, aulas que evidenciavam apenas suas participações, tendo como foco a explicação direta do conteúdo ou o uso inicial de desenhos ou o uso preliminar de material concreto. Desse modo, os aspectos de referência no ensino, relacionados a se permitir aos alunos resolverem sozinhos e apresentar suas estratégias, a discutir essas estratégias e a de articulá-las ao novo assunto, tiveram uma baixa porcentagem de indicação.

Contudo, apesar do processo formativo à docência nos anos iniciais, favorecido na disciplina ministrada às futuras professoras para tratarem do conteúdo de frações na abordagem da resolução de problemas, ainda se verificam participantes que não ampliaram seus conhecimentos sobre essa abordagem de ensino como um conhecimento pedagógico do conteúdo. Dificuldades sobre o significado do todo no conceito de fração e, sobretudo, não indicar o problema como ponto de partida na introdução de um tópico podem levar a um ensino que não valorize a compreensão dos alunos. Assim, no início, apenas $36 \%$ dessas licenciandas contemplaram em suas explicações os quatro aspectos do trabalho na abordagem da resolução de problemas e, ao final, houve um aumento para somente $44 \%$.

Como implicações educacionais, tendo em vista o procedimento teórico-metodológico adotado nesta pesquisa, as ações no ensino baseadas nos quatro aspectos (problema como ponto de partida; permitir aos alunos expor suas estratégias; discutir as estratégias dos alunos; articular estratégias dos alunos ao conteúdo) poderiam ser consideradas nas aulas de 
Matemática, sendo o foco o de favorecer aos alunos da escola a compreensão de conceitos e procedimentos matemáticos na abordagem da resolução de problemas.

Além disso, no caso de se propor o problema como ponto de partida, é importante apresentá-lo de forma que não leve o aluno ao uso direto de um algoritmo específico. Na perspectiva de Cai e Lester (2012, p. 157), “[...] os professores precisam ser estratégicos ao selecionarem tarefas apropriadas e conduzirem o discurso de sala de aula para maximizarem as oportunidades de aprendizagem".

Assim, pesquisas envolvendo a análise desses quatro aspectos de referência poderiam ser realizadas na formação de professores que ensinam Matemática em outros conteúdos, o que permitiria ampliar ações em cada um deles. Além disso, como neste artigo mostramos que apenas $44 \%$ das participantes abordaram os quatro aspectos de referência e que $40 \%$ não mencionaram a abordagem do problema como ponto de partida, pesquisas sobre uma formação articulada ao estágio poderiam ajudar a evidenciar possibilidades e limites na busca de condições para ampliar conhecimentos de futuros professores de Pedagogia para ensinar frações via resolução de problemas.

\section{Referências}

BOGDAN, R.; BIKLEN, S. Investigação Qualitativa em Educação. Uma introdução à teoria e aos métodos. Porto: Porto, 1994.

BRASIL. Ministério da Educação. Plano de Desenvolvimento da Educação: Prova Brasil: ensino fundamental: matrizes de referência, tópicos e descritores. Brasília: MEC, SEB; Inep, 2011.

BRASIL. Ministério da Educação. Resolução CNE/CP 1/2006. Diretrizes Curriculares Nacionais para o Curso de Graduação em Pedagogia, licenciatura. Brasília: MEC/CNE, 15 de maio de 2006.

BRASIL. Secretaria de Ensino Fundamental. Parâmetros Curriculares Nacionais: matemática, $1^{\circ}$ e $2^{\circ}$ Ciclos. Brasília: SEF/MEC, 1997.

BRITO, M. R. F. Alguns aspectos teóricos e conceituais da solução de problemas matemáticos. In: BRITO, M. R. F. (Org.). Solução de problemas e a matemática escolar. Campinas: Alínea, 2006, p. $13-53$.

BURNS, M. How to teach problem solving. Arithmetic Teacher, Reston, v. 29 n. 6, p. 46-49, Feb. 1982.

CAI, J.; LESTER, F. Por que o ensino com resolução de problemas é importante para a aprendizagem do aluno? Boletim GEPEM, Rio de Janeiro, v. 36, n. 60, p. 147-162, jan./jun. 2012.

CAMPOS, T. M. M.; MAGINA, S.; NUNES, T. O professor polivalente e a fração: conceitos e estratégias de ensino. Educação Matemática Pesquisa, São Paulo, v. 8, n. 1, p. 125-136, jan./jun. 2006. 
CAMPOS, T. M. M.; SILVA, A. F. G. Conhecimento profissional docente de professoras das séries iniciais da educação básica acerca da equivalência de números racionais na representação fracionária em um processo de formação continuada. Revemat, Florianópolis, v. 4, n. 1, p.114-127, 2009.

CARLINI, A. L. Procedimentos de ensino: escolher e decidir. In: SCARPATO, M. (Org.). Os procedimentos de ensino fazem a aula acontecer. São Paulo: Avercamp, 2004, p. 25-81.

CHI, M. T. H.; GLASER, R. A capacidade para a solução de problemas. In: STERNBERG, R. As capacidades intelectuais humanas: uma abordagem em processamento de informações. Traduçao de: Dayse Batista. Porto Alegre: Artes Médicas, 1992, p. 249-275.

CHARLES, R. I. Teacher education and mathematical problem solving: some issues and directions. In: CHARLES, R. I.; SILVER, E. A. (Ed.). The teaching and assessing of mathematical problem solving. Virginia: Lawrence Erlbaum Associates, 1990, p. 259-272.

CHARLES, R. I. The role of problem solving. Arithmetic Teacher, Reston, v. 32, p. 48-50, Feb. 1985.

COSTA, N. M. L.; POLONI, M. Y. Percepções de concluintes de pedagogia sobre a formação inicial do professor para a docência de matemática. Bolema, Rio Claro, v. 26, n. 44, p. 1289-1314, dez. 2012.

CRUZ, B. C. A formação profissional específica nos cursos de licenciatura em pedagogia: a apropriação de saberes para a docência. 2011. 135 f. Dissertação (Mestrado em Educação) - Faculdade de Educação, Pontifícia Universidade Católica, Goiás, 2011.

ECHEVERRÍA, M. P. P. A solução de problemas em matemática. In: POZO, J. I. (Org.). A solução de problemas: aprender a resolver, resolver para aprender. Porto Alegre: ArtMed, 1998, p. 43-65.

FI, C. D.; DEGNER, K. M. Teaching through problem solving. Mathematics Teacher, Reston, v. 105, n. 6, Feb. p. 455-459, Feb. 2012.

GUÉRIOS, E.; LIGESKI, A. I. S. Resolução de problema em matemática na educação básica: problema em matemática ou em linguagem? In: CONGRESO IBEROAMERICANO DE EDUCACIÓN MATEMÁTICA, 7., 2013. Montevidéu-Uruguai. Anais... Montevidéu: VII CIBEM, 2013.

KRULIK, S.; RUDNICK, J. A. Teaching problem solving to preservice teachers. Arithmetic Teacher, Reston, v. 29, n. 6, p. 42-45, Feb. 1982.

KRUTETSKII, V. A. The psychology of mathematical abilities in schoolchildren. Translation: Joan Teller. Chicago: University of Chicago Press, 1976.

MAGINA, S.; CAMPOS, T. A fração nas perspectivas do professor e do aluno dos dois primeiros ciclos do ensino fundamental. Bolema, Rio Claro, v. 21, n. 31, p. 23-40, dez. 2008.

MARQUES, W. C. Narrativas sobre a prática de ensino de matemática de professores dos anos iniciais do ensino fundamental. 2013. 284 f. Dissertação (Mestrado em Educação Matemática) Instituto de Geociências e Ciências Exatas, UNESP, Rio Claro, 2013.

MAYER, R. E. Thinking, problem solving, cognition. 2. ed. New York: WH Freeman and Company, 1992.

MENEGAZZI, M. O estudo de frações: uma experiência no curso de pedagogia. Revemat, Florianóplois, v. 08, n. 1, p. 248-265, jan./jun. 2013. 
MIZUKAMI, M. G. N. Aprendizagem da docência: conhecimento específico, contextos e práticas pedagógicas. In: NACARATO, A. M.; PAIVA, M. A. V. (Org.). A formação do professor que ensina matemática: perspectivas e pesquisas. Belo Horizonte: Autêntica, 2006, p. 213-231.

ORTEGA, E. M. V.; SANTOS, V. M. A matemática e o lugar do professor nos anos iniciais: o ponto de vista dos alunos da pedagogia. Revista Eletrônica de Educação, São Carlos, v. 6, n. 1, p. 27-43, mai. 2012.

PIROLA, N. A. et al. Resolução de problemas com informações supérfluas: uma análise do desempenho de alunos sob a ótica da teoria de Krutetskii. In: SEMINÁRIO INTERNACIONAL DE PESQUISA EM EDUCAÇÃO MATEMÁTICA, 3., 2006, Águas de Lindóia. Anais... Águas de Lindóia: SBEM, 2006.

POLYA, G. A arte de resolver problemas: um novo aspecto do método matemático. Tradução de: Heitor Lisboa de Araújo. Rio de Janeiro: Interciência, 1978.

POZO, J. I; ANGÓN, Y. M. A solução de problemas como conteúdo procedimental da educação básica. In: POZO, J. I. (Org.). A solução de problemas: aprender a resolver, resolver para aprender. Porto Alegre: ArtMed, 1998, p. 139-165.

PROENÇA. M. C.; PIROLA, N. A. A resolução de problemas no contexto do estágio curricular supervisionado: dificuldades e limites de licenciandos em matemática, Revemat, Florianópolis, v. 9, n. 1, p. 119-138, jan./jun. 2014.

PROENÇA. M. C.; PIROLA, Análise do desempenho de licenciandos em Matemática na resolução de problemas. In: CONFERÊNCIA INTERAMERICANA DE EDUCAÇÃO MATEMÁTICA, 13., 2011. Recife-PE. Anais... Recife: XIII CIAEM, 2011.

PROENÇA, M. C. Os conhecimentos de licenciandos em matemática sobre a resolução de problemas. In: CONGRESO IBEROAMERICANO DE EDUCACIÓN MATEMÁTICA, 7., 2013. MontevidéuUruguai. Anais... Montevidéu: CIBEM, 2013a.

PROENÇA, M. C. Resolução de problemas e formação de professores que ensinam matemática: análise dos trabalhos do encontro nacional de educação matemática. In: ENCONTRO NACIONAL DE EDUCAÇÃO MATEMÁTICA, 11., 2013. Curitiba-PR. Anais... Curitiba: SBEM, 2013 b.

ROLDÃO, M. C. Formar para a excelência profissional: pressupostos e rupturas nos níveis iniciais da docência. Educação e Linguagem, São Paulo, v. 10, n. 15, p. 18-42, jan/jun. 2007.

SANTOS, M. C.; ORTIGÃO, M. I. R.; AGUIAR, G. S. Construção do Currículo de Matemática: como os professores dos anos iniciais compreendem o que deve ser ensinado? Bolema, Rio Claro, v. 28, n. 49, p. 638-661, ago. 2014.

SCHOENFELD, A. H. Problem solving in context(s). In: CHARLES, R. I.; SILVER, E. A. (Ed.). The teaching and assessing of mathematical problem solving. 3. ed. Virginia: Lawrence Erlbaum Associates, 1990, p. 82-92.

SCHROEDER, T. L.; LESTER, F. K., JR. Developing understanding in mathematics via problem solving. In: TRAFTON, P. R.; SHULTE, A. P. (Ed.). New directions for elementary school mathematics. Reston: NCTM, 1989, p. 31-42.

SHULMAN, L. S. Knowledge and teaching: foundations of the new reform. Harvard Educational Review, Cambridge, v. 57, n. 1, p. 01-22, Feb. 1987. 
SHULMAN, L. S. Those Who understand: knowledge growth in teaching. Educational Researcher, Washington, v. 15, n. 2, p. 04-14, Feb. 1986.

STERNBERG, R. Psicologia cognitiva. Tradução de: Maria Regina Borges Osório. Porto Alegre: ArtMed, 2000.

Submetido em Junho de 2014. Aprovado em Fevereiro de 2015. 